\title{
Nutritional Intervention at a Girl's Orphanage in Sri Lanka Decreased Stunting after One Year
}

\author{
Sigal Eilat-Adar ${ }^{*}$, Isabel Periquito ${ }^{2}$, Alice Mo $^{3}$, Aviva Zeev ${ }^{4}$, Rachel Golan ${ }^{5}$, Naresh Gunaratnam ${ }^{6}$ \\ ${ }^{1}$ Head of the Masters in Healthy and Active Lifestyle Program, The Academic College at Wingate, Wingate Institute, \\ Netanya, Israel \\ ${ }^{2}$ World Health Organization, Copenhagen V, Denmark \\ ${ }^{3}$ American Academy of Pediatrics, Retired from Scripps Clinic Medical Group, San Diego, CA, USA \\ ${ }^{4}$ The Academic College at Wingate, Wingate Institute, Netanya, Israel \\ ${ }^{5}$ Department of Public Health, Faculty of Health Sciences, Ben-Gurion University of the Negev, Beer-Sheva, Israel \\ ${ }^{6}$ Huron Gastro Center for Digestive Care, Ann Arbor, MI, USA \\ Email: ^Sigaleilat70@gmail.com, not.izzy@gmail.com, alicemo@me.com, avivaz@wincol.ac.il, golanra@exchange.bgu.ac.il, \\ naresh.gunaratnam@gmail.com
}

How to cite this paper: Eilat-Adar, S., Periquito, I., Mo, A., Zeev, A., Golan, R. and Gunaratnam, N. (2021) Nutritional Intervention at a Girl's Orphanage in Sri Lanka Decreased Stunting after One Year. Health, 13, 60-67.

https://doi.org/10.4236/health.2021.131006

Received: December 25, 2020

Accepted: January 23, 2021

Published: January 26, 2021

Copyright $\odot 2021$ by author(s) and Scientific Research Publishing Inc. This work is licensed under the Creative Commons Attribution International License (CC BY 4.0).

http://creativecommons.org/licenses/by/4.0/ (c) (i) Open Access

\begin{abstract}
Background: Both the civil war in 1998 and the tsunami in 2004 in Sri Lanka resulted in a large number of orphans. Objective: To examine the effect of nutritional intervention on one-year period of stunting and/or emaciated status. Methods: Study setting: Twenty-eight girls aged 5 - 19 years old were in the care of Grace Girls Home, an orphanage for girls located in the port town of Trincomalee, Sri Lanka, at the time of the survey. Nineteen of them had two available anthropometric measurements recorded over one year of follow-up. Anthropometric measurements were obtained prior to the intervention of nutritional mentoring to the local caregivers, and one year after intervention. Height-for-age, weight-for-age, and BMI-for-age z-scores were calculated using SMART methodology. Nutritional consultancy recommended an additional 15 - 20 grams of high quality protein per day, which was given to the girls. The kitchen team was encouraged to regularly prepare a variety of pulse-based dishes, using local foods and recipes. The local palm oil, rich in saturated fatty acids, was replaced with sunflower oil, rich in polyunsaturated fatty acids. Results: Stunting was decreased from Height to age Z-score $(-1.19 \pm 0.94)$ to $(-0.90 \pm 1.06)(\mathrm{P}=0.016)$, and BMI Z-score from $(-0.80 \pm 0.79)$ to $(-0.50 \pm 0.74)(P=0.004)$. Conclusions: A single nutritional education intervention, culturally adapted and implemented by the local caregivers, can decrease stunting in orphans within one year.
\end{abstract}

\section{Keywords}

Orphans, Sri Lanka, BMI, Z-Score, Stunting 


\section{Introduction}

Sri Lanka experienced a number of foreign invasions from the $15^{\text {th }}$ century until 1948, when it finally gained its independence. Forty years later the island suffered a violent political crisis [1]. In 2004 a deadly tsunami took the lives of nearly 40,000 Sri Lankans, and left hundreds of thousands homeless. Both the civil war in 1988 and the tsunami created a large number of orphans, especially in coastal areas of the country.

According to the latest anthropometric data from the Demographic Health Survey (DHS) [2] for Sri Lanka, between the years 2006-2007, 17.3\% of children under the age of 5 were stunted (or short for their age), while $14.7 \%$ were emaciated (or too thin for their height), and $21.1 \%$ were underweight, which may reflect being stunted, emaciated, or both. According to the same survey, in the Trincomalee district, an area of $2727 \mathrm{~km}^{2}$ located in the east of Sri Lanka, in the Eastern province, the prevalence of these conditions was even higher, where $30.5 \%$ of children under the age of five were stunted, of which $11.3 \%$ were severely stunted. Moreover, according to the World Health Organization (WHO), in 2018 life expectancy at birth for both sexes in Sri Lanka was 74.9 years, yet healthy life expectancy was only 67 years [3].

Grace Girls Home (GRACE), which opened in August 2002, is an orphanage for girls located on seven beachfront acres in the port town of Trincomalee. Girls admitted to this institution suffered the loss of their immediate family, and had limited opportunities to attend school or gain learning skills. GRACE has an 18-year record of empowering girls and developing educational and vocational programs to help them break the cycle of poverty.

Childhood stunting is linked to short adult stature, reduced lean body mass, fewer years of schooling, diminished intellectual functioning, and reduced earnings [4]. Moreover, early life stress may be associated with early pathways to cardiovascular and metabolic risk in youths, even after moving into well-resourced homes early in life and in the absence of increased adiposity [5]. Stunting is a cyclical process, as women who were themselves stunted in childhood tend to have stunted offspring, creating an intergenerational cycle of poverty and reduced human capital that is difficult to break.

Stunting (being too short for age), was initially viewed as a condition determined in the first 1000 days of life, because linear growth failure begins antenatally. However, it was later proposed that the window of opportunity for catch-up growth may extend beyond 24 months, [6] and potential windows of opportunity to exit this cycle have been identified [7].

High-quality protein intake plays an important role in fighting malnutrition [8]. This includes animal protein, dairy products, and eggs. Interventions with milk and fortified milk were found to be culturally acceptable and well-tolerated across study populations [9]. In a study by Sadik, among 40 children aged 2 - 18 in Ghana, the top five most frequently consumed foods were: coffee, tea, maize, bread, and white rice, which led to $10 \%$ of children being stunted and $10 \%$ wasted (too thin for height) [10]. Legumes and pulses rich in high-quality pro- 
tein comprise the largest portion in a typical South-Asian diet plate [11].

The objective of the current study was to first evaluate the nutritional status of the residents at GRACE and to estimate the burden of being stunted and/or emaciated, and then, to examine the effect of a nutritional intervention one-year post-intervention.

\section{Materials and Methods}

This is a prospective study design.

\subsection{Participants}

Twenty-eight girls aged 5 - 19 years-old who were residents at GRACE were included in the study. Nineteen of them had two repeated measurements taken over one year. The other participants were absent from the orphanage during the second day of measurements due to having to attend classes.

\subsection{Measurements}

Anthropometric measurements were obtained prior to the intervention and one year after, using the Standardized Monitoring and Assessment of Relief and Transitions (SMART) [12], which is a standardized, simplified, cross-sectional field survey method designed to aid the collection of quality, up-to-date and timely nutrition data necessary for decision-making. The methodology was developed to harmonise methods for nutrition assessments, especially during emergencies.

\subsection{Intervention Methodology}

Meal preparation and dining observations were conducted during one full week. Both the kitchen teams and the residents at GRACE received nutritional counselling during and after meals, for three full days.

The nutrition intervention focused on increasing high-quality protein by adding one egg (adding $\sim 7$ grams of protein) and one glass of milk (adding $\sim 6$ grams of protein) once a day. Due to sanitation considerations it was necessary to use milk powder [13]. Kitchen teams were encouraged to regularly prepare a variety of pulse-based dishes, in addition to an increase of $20-30$ grams of chicken at least twice a week (adding $\sim 8$ grams of protein). This resulted in an addition of 15 - 20 grams of protein per day, for each girl.

Cooking oil was changed from palm oil, rich in saturated fatty acids, to sunflower oil, rich in polyunsaturated fatty acids [14].

\subsection{Statistical Analysis}

Age was recorded, and the duration of living at GRACE was determined using the date of admission. Earlier data were retrieved from medical records available at GRACE. The WHO 2007 growth reference population was used to calculate the height-for-age, weight-for-age, and BMI-for-age z-scores (HAZ, WAZ, and BMIZ, respectively). The distributions of $z$-scores were analyzed with descriptive and in- 
ferential statistical methods. Data were described as mean values and standard deviation (SD) for continuous variables. Spearman correlation was used to assess the association between time living at GRACE and the anthropometric indexes, i.e. HAZ, WAZ, and BMIZ. A paired t-test was used to assess the difference between the different anthropometric indexes between 2016 and 2017.

Anthropometric data were completed using WHO AnthroPlus software [15]. The statistical analysis was performed using SPSS version 25. Informed consent was obtained from each girl's guardian. The study was approved by the Wingate College ethical committee.

\section{Results}

The final sample included 28 girls with measures collected in 2016. Data for 2017 were available for 19 girls out of this sample (68\%). Demographic and anthropometric data are presented in Table 1 . No differences were found between the group of 19 girls compared to the 9 girls for whom we did not have data from 2017.

Results from Table 1 show that nutritional indexes WAZ (mean $=-0.49$, SD $=0.92$ ) and BMIZ (mean $=-0.80, \mathrm{SD}=0.79)$ were within the normal parameters, and HAZ (mean $=-1.19, \mathrm{SD}=0.94$ ) indicated a mild stunting problem among the girls residing at GRACE.

The correlations between the anthropometric parameters, age, and time at GRACE in 2016 are presented in Table 2. Although Z-scores are not expected to be associated with time since they are adjusted for age, this table shows a significant correlation between BMIZ and age $(r=0.83)$, as well as with time in GRACE $(r=0.75)$, was found, indicating that a longer stay at GRACE may have led to a better nutritional status. No association was found with HAZ.

One year after the nutritional intervention, we compared the Z-scores between 2016 and 2017. Changes in Z-scores for height, weight, and BMI are presented in Table 3. In the table, a significant improvement in both height ( $\mathrm{p}=$ $0.016)$ and BMI Z-scores $(p=0.004)$ following the intervention is presented. Figure 1 shows the changes in weight, height and BMI Z-scores in a box plot

Table 1. Baseline characteristics of GRACE study population $n=19^{*}$.

\begin{tabular}{ccc}
\hline & Mean & SD \\
\hline Age at entrance (years) & 9.13 & 2.87 \\
Time at GRACE (years) & 6.17 & 4.69 \\
Age (years) & 14.56 & 4.53 \\
Current weight (kg) & 39.03 & 10.89 \\
Current height (m) & 1.44 & 0.14 \\
BMI & 17.35 & 2.93 \\
Weight for age Z-score (WAZ) & -0.49 & 0.92 \\
Height for age Z-score (HAZ) & -1.19 & 0.94 \\
BMI for age Z-score (BMIZ) & -0.80 & 0.79
\end{tabular}

${ }^{\star}$ Measurements available for participants in 2016 and 2017. 
Table 2. Association between anthropometric parameters, age, and time living at GRACE.

\begin{tabular}{cccccc}
\hline & \multicolumn{2}{c}{ Time at GRACE } & \multicolumn{2}{c}{ Age } \\
\cline { 2 - 5 } & $\mathrm{r}$ & $\mathrm{p}$ & $\mathrm{r}$ & $\mathrm{p}$ \\
\hline Weight-for-age Z-score (WAZ) & 0.50 & 0.03 & 0.76 & $<0.001$ \\
Height-for-age Z-score (HAZ) & 0.05 & 0.84 & 0.24 & 0.33 \\
BMI for age Z-score (BMIZ) & 0.75 & $<0.01$ & 0.83 & $<0.01$ \\
\hline
\end{tabular}

Table 3. Changes in anthropometric parameters after one year of follow-up $n=19$.

\begin{tabular}{|c|c|c|c|c|c|}
\hline & \multicolumn{2}{|c|}{ Baseline } & \multicolumn{2}{|c|}{1 year post-intervention } & \multirow[b]{2}{*}{ p-value } \\
\hline & Mean & $\mathrm{SD}$ & Mean & $\mathrm{SD}$ & \\
\hline Time at GRACE (years) & 6.47 & 4.77 & & & \\
\hline Age (years) & 15.79 & 4.64 & & & \\
\hline Weight (kg) & 37.0 & 11.4 & 39.0 & 10.9 & $<0.001$ \\
\hline Height (m) & 1.43 & 0.14 & 1.45 & 0.12 & \\
\hline BMI & 17.4 & 2.9 & 18.1 & 3.00 & \\
\hline Weight for age Z-score (WAZ) & -0.49 & 0.92 & -0.30 & 0.64 & 0.025 \\
\hline Height for age Z-score (HAZ) & -1.19 & 0.94 & -0.90 & 1.06 & 0.016 \\
\hline BMI for age Z-score (BMIZ) & -0.80 & 0.79 & -0.50 & 0.74 & 0.004 \\
\hline
\end{tabular}

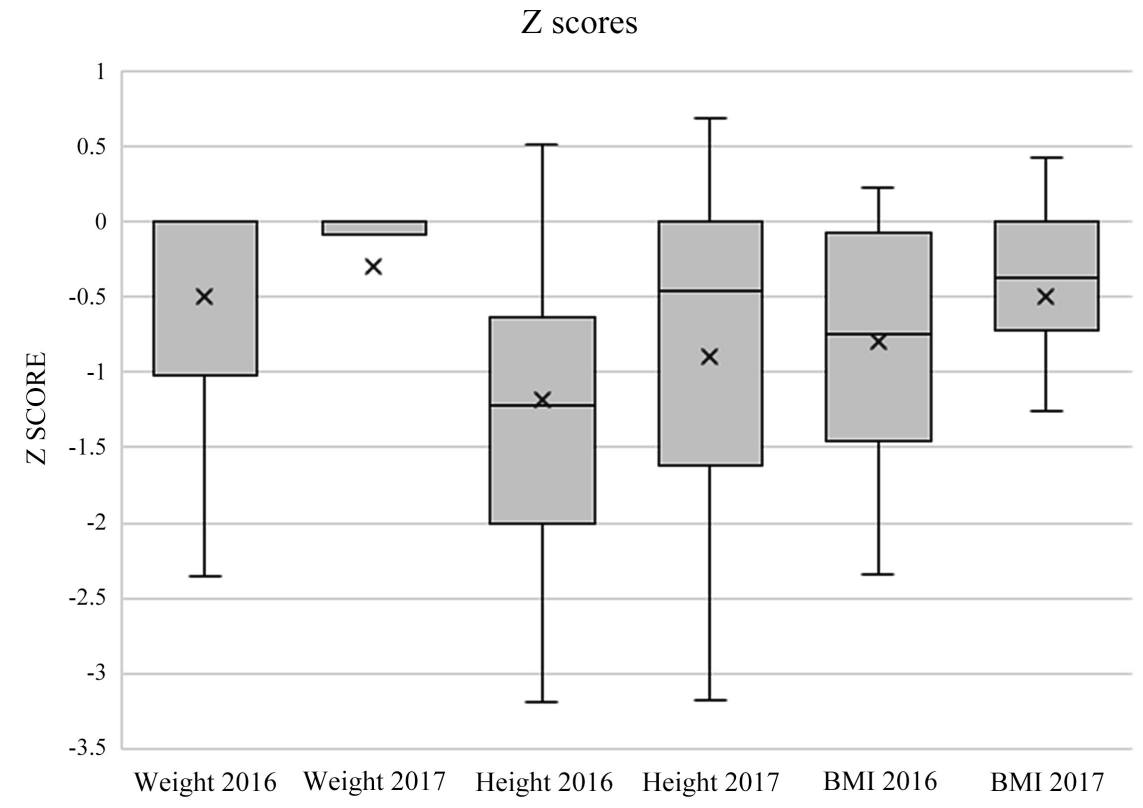

Figure 1. Box plot of changes in weight, height and BMI Z-scores.

\section{Discussion}

In this study we showed how a single nutritional education intervention, implemented by the local caregivers, can decrease stunting in orphans. The improvement in stunting measures was achieved within one year.

The early years of life have an important influence on health and growth [16]. 
Since the average age of the girls' entering GRACE was 9.13 years, it was assumed that the prevailing stunting problems were due to the poor conditions during their early years of life. The baseline conditions of these girls show that their major nutritional problem was stunting, likely attributable to poor nutrition and disease during the girls' first years of life, prior to entering GRACE. Stunted growth reflects a process of failure to reach the linear growth potential due to suboptimal health and/or nutritional conditions. It is widely recognized that the "window of opportunity" for reducing the chance of stunting is the first 1000 days-from inception to a child's second birthday. However the results of the current study support the theory that windows of opportunity for different components of the stunting syndrome may open and close at different times, and that adolescence is the period of time beyond infancy when growth velocity is maximal and represents the last opportunity for catch-up growth [6].

Children from low- and middle-income countries tend to be stunted and underweight [17]. Some studies have shown the presence of growth retardation in orphans living in orphanages, with an improvement in their nutritional status achieved only after they were adopted by families [18] [19]. Results of the current study show that improvement in nutritional status can be achieved by other means, and not only after adoption. A single week-long nutritional intervention in nutrition education and consultancy achieved a positive association between time living in an orphanage and improved weight and BMI Z-scores. The stunting score was not associated with length of stay at the orphanage, and changed only after the supplement with high-quality protein was provided. Determining the long-term health changes that take place with the substitute of unsaturated sunflower oil for saturated palm oil requires a much longer follow-up.

This study has several limitations. First, this is a post-hoc analysis, where the BMIZ at entrance to the orphanage is missing. Second, we are limited by the small sample size and selected population, with no control group. Nutrition is essential for growth, however other factors should be addressed in the treatment of these young orphans, such as depression, low self-esteem [20] and psychological well-being [21]. Strengths of the current study include the fact that this is the first nutritional assessment of orphans in Sri Lanka, and that the implementation of the intervention was done by the local caregivers. The results also show that even a single nutritional intervention, implemented by the local caregivers, can decrease stunting in orphans during one year.

In conclusion, our findings suggest that a single nutritional intervention, which includes an increase in protein intake, can decrease the prevalence of stunting and improve BMI scores during one year of follow-up.

\section{Acknowledgements}

The authors would like to thank Ms. Angela Vignewsaran for her collaboration and friendship, and Dinah Olswang for her editing. 


\section{Conflicts of Interest}

The authors declare no conflicts of interest regarding the publication of this paper.

\section{References}

[1] Arasaratnam, S. and Peiris, G.H. (2020) Sri Lanka. Encyclopedia Britannica. https://www.britannica.com/place/Sri-Lanka

[2] Department of Census and Statistics (2017) Demographic and Health Survey 2006-2007.

https://catalog.ihsn.org/index.php/catalog/2551http://www.statistics.gov.lk/social/D HS\%20200607\%20FinalReport.pdf

[3] World Health Organization (WHO) (2018) Health SDG Profile: Sri Lanka. https://apps.who.int/iris/bitstream/handle/10665/276842/sdg-profile-SriLanka-eng. pdf? sequence $=5$ \&isAllowed $=y \& u a=1 \#: \sim:$ text $=$ Life $\% 20$ expectancy $\% 20$ at $\% 20$ birth $\% \mathrm{E}$ 2\%81\%B4\%20provides,health\%20for\%20the\%20country's\%20population

[4] Victora, C.G., Adair, L., Fall, C., Hallal, P.C., Martorell, R., Richter, L. and Sachdev, H.S. (2008) Maternal and Child Undernutrition: Consequences for Adult Health and Human Capital. The Lancet, 371, 340-357. https://doi.org/10.1016/S0140-6736(07)61692-4

[5] Reid, B.M., Harbin, M.M., Arend, J.L., Kelly, A.S., Dengel, D.R. and Gunnar, M.R. (2018) Early Life Adversity with Height Stunting Is Associated with Cardiometabolic Risk in Adolescents Independent of Body Mass Index. The Journal of Pediatrics, 202, 143-149. https://doi.org/10.1016/j.jpeds.2018.06.047

[6] Predrendergast, A.J. and Humphrey, J.H. (2014) The Stunting Syndrome in Developing Countries. Paediatrics and International Child Health, 34, 250-265. https://doi.org/10.1179/2046905514Y.0000000158

[7] Martorell, R. and Zongrone, A. (2012) Intergenerational Influences on Child Growth and Undernutrition. Paediatric and Perinatal Epidemiology, 26, 302-314. https://doi.org/10.1111/j.1365-3016.2012.01298.x

[8] Hossain, M., Choudhury, N., Adib Binte Abdullah, K., Mondal, P., Jackson, A.A., Walson, J. and Ahmed, T. (2017) Evidence-Based Approaches to Childhood Stunting in Low and Middle Income Countries: A Systematic Review. Archives of Disease in Childhood, 102, 903-909. https://doi.org/10.1136/archdischild-2016-311050

[9] Dror, D.K. and Allen, L.H. (2011) The Importance of Milk and Other Animal-Source Foods for Children in Low-Income Countries. Food Nutrition Bulletin, 32, 227-243. https://doi.org/10.1177/156482651103200307

[10] Sadik, A. (2010) Orphanage Children in Ghana: Are Their Dietary Needs Met? Pakistan Journal of Nutrition, 9, 844-852. https://doi.org/10.3923/pjn.2010.844.852

[11] Silva, V., Jayasinghe, M.A., Senadheera, S.A. and Ranaweera, K.K.D.S. (2020) Determination of Macronutrient Compositions in Selected, Frequently Consumed Cereals, Cereal Based Foods, Legumes and Pulses Prepared According to Common Culinary Methods in Sri Lanka. Journal of Food Science and Technology, 57, 816-820. https://doi.org/10.1007/s13197-019-04085-X

[12] SMART (2006) Measuring Mortality, Nutritional Status, and Food Security in Crisis Situations: SMART Methodology. http://www.nutrisurvey.de/ena beta/SMART Methodology 08-07-2006.pdf

[13] Kalyankar, S.D., Deshmukhs, A.M., Chopde, S., Khedkar, C.D. and Lules, S. (2016) Milk Powder. In: Caballero, B., Finglas, P.M. and Toldrá, F., Eds., Encyclopedia of 
Food and Health, Elsevier, Amsterdam, 724-728.

https://doi.org/10.1016/B978-0-12-384947-2.00465-7

[14] Schwingshackl, L., Bogensberger, B., Benčič, A., Knüppel, S., Boeing, H. and Hoffmann, G. (2018) Effects of Oils and Solid Fats on Blood Lipids: A Systematic Review and Network Meta-Analysis. Journal of Lipid Research, 59, 1771-1182.

https://doi.org/10.1194/jlr.P085522

[15] WHO (2020) Growth Reference 5-19 Years. https://www.who.int/growthref/en

[16] Grantham-McGregor, S., Cheung, Y.B., Cueto, S., Glewwe, P., Richter, L., Strupp, B. and International Child Development Steering Group (2007) Developmental Potential in the First 5 Years for Children in Developing Countries. The Lancet, 369, 60-70. https://doi.org/10.1016/S0140-6736(07)60032-4

[17] de Onis, M., Garza, C., Victora, C.G., Onyango, A.W., Frongillo, E.A. and Martines, J. (2004) The WHO Multicentre Growth Reference Study Planning, Study Design, and Methodology. Food and Nutrition Bulletin, 2, S15-S26.

https://doi.org/10.1177/15648265040251S103

[18] Le Mare, L. and Audet, K. (2006) A Longitudinal Study of the Physical Growth and Health of Postinstitutional Romanian Adoptees. Paediatric Child Health Journal, 11, 85-91.

[19] Rutter, M. (1998) Developmental Catch-Up, and Deficit, Following Adoption after Severe Global Early Privation. English and Romanian Adoptees (ERA) Study Team. Journal of Child Psychology and Psychiatry, 39, 465-476. https://doi.org/10.1111/1469-7610.00343

[20] He, Z. and Ji, C. (2007) Nutritional Status, Psychological Well-Being and the Quality of Life of AIDS Orphans in Rural Henan Province, China. Tropical Medicine \& International Health, 12, 1180-1190. https://doi.org/10.1111/j.1365-3156.2007.01900.x

[21] Hailegiorgis, M.T., Berheto, T.M., Sibamo, E.L., Asseffa, N.A., Tesfa, G. and Birhanu, F. (2018) Psychological Wellbeing of Children at Public Primary Schools in Jimma Town: An Orphan and Non-Orphan Comparative Study. PLoS ONE, 13, e0195377. https://doi.org/10.1371/journal.pone.0195377 